\title{
Non-invasive monitoring of endocrine status in laboratory primates: methods, guidelines and applications
}

\author{
M. Heistermann \\ Reproductive Biology Unit, German Primate Center, Kellnerweg 4, 37077 Goettingen, Germany
}

Received: 5 November 2009 - Revised: 11 October 2010 - Accepted: 20 October 2010 - Published: 12 November 2010

\begin{abstract}
During the past three decades, non-invasive methods for assessing physiological, in particular endocrine, status have revolutionized almost all areas of primatology, including behavioural ecology, reproductive biology, stress research, conservation and last but not least management of primates in captivity where the technology plays an integral role in assisting the husbandry, breeding and welfare of many species. Noninvasive endocrine methods make use of the fact that hormones circulating in blood are secreted into saliva or deposited in hair and are eliminated from the body via urinary and faecal excretion. The choice of which matrix to use for hormonal assessment depends on a range of factors, including the type of information required, the measurement techniques involved, species differences in hormone metabolism and route of excretion and the practicality of sample collection. However, although sample collection is usually relatively easy, analysing hormones from these non-invasively collected samples is not as easy as many people think, particularly not when dealing with a new species. In this respect, the importance of a careful validation of each technique is essential in order to generate meaningful and accurate results. This paper aims to provide an overview of the available non-invasive endocrine-based methodologies, their relative merits and their potential areas of application for assessing endocrine status in primates, with special reference to captive environments. In addition, general information is given about the most important aspects and caveats researchers have to be aware of when using these methodologies.
\end{abstract}

\section{Introduction}

Since many years, primates are kept and bred in captivity for biological and biomedical research or for propagation of endangered species. Under such conditions of intensive management, the ability to monitor physiological, in particular hormonal (endocrine) status plays an integral role in assisting the husbandry, breeding and welfare of many species (Lasley and Savage, 2007). For example, endocrine monitoring is of key importance in understanding the complex reproductive biology of primates on which subsequently husbandry and management strategies that facilitate attempts to enhance successful production of offspring (by either natural breeding or assisted means) can be developed. In addition, monitoring of endocrine status allows evaluating aspects of animal welfare, also a key management issue when maintain-

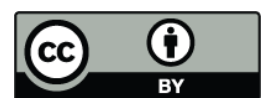

Correspondence to: M. Heistermann (mheiste@gwdg.de) ing primates in a captive situation. Furthermore, endocrine monitoring can be useful for evaluating the potential impact of an individual's physiological state (e.g. stress status, ovarian cycle state) on research data collected, thereby helping to improve assessment of data reliability. Last but not least, many research studies themselves require information on an animal's endocrine state, for instance in studies focussing on the stress axis, information on the endocrine activity of the adrenal gland (and thus secretion of glucocorticoid (stress) hormones) is usually of key importance.

Measurement of hormones in blood (the traditional medium for endocrine analysis), is still probably the most informative and widely used approach for monitoring endocrine function in many laboratory and domestic animal species and is also applied in studies using laboratory primates (see Lasley and Savage, 2007 for references). However, general difficulties associated with capture and restraint necessary for the collection of blood samples (e.g. sedation) and the potential negative impact of these invasive and generally stressful procedures on an animal's behaviour and 
physiology itself (e.g. Reeder and Kramer, 2005) render this approach usually impractical for routine (i.e. repeated and/or regular) application. Except situations where there are no suitable alternatives or where husbandry practices and/or degree of animal training are of sufficient level that venipuncture represents little risk or stress to the animal (e.g. Prescott and Buchanan-Smith, 2003), the usually intractable nature of primates as well as ethical considerations emphasises the importance of monitoring methods based on non-invasive sample collection (e.g. urine, faeces, see below) by which direct animal contact can be largely (or completely) avoided. Such non-invasive approach provides therefore a more suitable option for any longitudinal studies on physiology in conjunction with other parameters, such as behaviour and reproduction. Moreover, it provides the opportunity for generating physiological data from free-ranging primates living in their natural habitat, an area which has nowadays found widespread application in studies on behaviour, ecology, physiology and conservation of species from almost all taxa (see Whitten et al., 1998a; Hodges and Heistermann, 2011).

Any non-invasive endocrine procedure is based on the principle that hormones can be measured in biological matrices other than blood, e.g. urine, faeces, saliva and hair. The choice of which to use depends on a range of factors, including the type of information required, the measurement techniques involved, species differences in hormone metabolism and route of excretion and the practicality of sample collection, particularly when repeated sampling over extended periods is necessary. This paper aims to provide an overview of the available non-invasive endocrine-based methodologies, their relative merits and their potential areas of application for assessing endocrine status in primates, with special reference to captive environments. In addition, general information is given about the most important aspects researchers have to be aware of when using these methodologies to study captive-housed animals. For a comprehensive overview of the application of and specific requirements associated with these techniques for studies of wild primates, readers should consult Whitten et al. (1998a) and Hodges and Heistermann (2011).

\section{Sampling methods and applications}

Circulating hormones are mainly metabolized in the liver and/or kidney (rendering the hormone biologically impotent) before they are finally eliminated from the body mainly via excretion into the urine or faeces. Steroid hormones (e.g. stress hormones) are also deposited in hair and a small proportion of the active fraction of steroid and peptide/proteo-hormones in blood enters the saliva (see below). The four matrices therefore represent general sources from which hormones and/or their metabolites can be quantified with each matrix having its own intrinsic advantages and disadvantages and type of information that can be deduced from it.

\subsection{Hormone analysis from urine}

Historically and for many years urine has been the predominating source when information on endocrine status (mainly regarding female reproductive function) in primates was generated (see Lasley and Savage, 2007). Urine has a number of qualities that make it ideal as a sample for endocrine assessment. It is constantly produced and usually can be easily collected without capture or restraint over indefinite periods of time (Lasley and Savage, 2007). In addition, urine contains various classes of hormones; apart from the steroids (reproductive and stress hormones: estrogens, progestogens, androgens and glucocorticoids), it also contains proteo-hormones (e.g. gonadotropins: luteinizing hormone ( $\mathrm{LH})$, follicle-stimulating hormone (FSH), chorionic gonadotropin (CG)), peptide hormones (e.g. oxytocin, prolactin) and catecholamines (e.g. adrenaline, noradrenaline). Moreover, urine represents a matrix for measuring other (non-hormonal) physiological markers, such as C-peptide (a metabolic byproduct of insulin synthesis), a potentially useful marker for nutritional status and energetic condition in primates (see Deschner et al., 2008; Sherry and Ellison, 2007). Whereas quantifying steroid hormone metabolites from primate urine is straightforward, one important caveat is that peptide and proteo-hormones may be structurally heavily altered before excretion or not excreted in measurable amounts in urine. Moreover, the structure of these hormones is species-specific, making their measurement more challenging and multispecies application of assays difficult (e.g. Matteri et al., 1987; Matteri et al., 1990).

\subsubsection{Diurnal variation and urine collection}

Some hormones, such as testosterone and the stress hormone cortisol show a pronounced variation in secretion over the day (so-called diurnal pattern; e.g. Lerchl et al., 1991; Muller and Lipson, 2003; Smith and French, 1997). Therefore, time of urine collection is a variable that needs to be controlled for. Ideally, first morning urine should be collected since this represents the cumulative secretion and elimination of hormones over several hours. In case this is not possible, samples should be collected at roughly the same time of day in order to minimize the influence of diurnal variation on hormone levels. In captivity this should not be a problem since it is possible to condition most primates to urine collection by either training them to enter individual cages for a short period of time that allow urine to be collected directly upon voiding (Anzenberger and Gossweiler, 1993; Pryce et al., 1995) or to accept a person collecting a urine sample upon waking (e.g. Ziegler et al., 1993). Urine can also be collected by aspiration (using a pipette or syringe) from the (clean and dry) cage floor or from a container or sheet positioned under 
the cage. Animals can even be trained using positive reinforcement to give a urine sample on command (Deschner et al., 2008).

\subsubsection{Quantity of urine and indexing}

Urine volumes as small as $0.2-0.3 \mathrm{ml}$ are sufficient for most hormone analysis procedures (including the measurement of creatinine or specific gravity for indexing purposes, see below), and it is generally not necessary to collect more than $1.0 \mathrm{ml}$. If possible, samples should be centrifuged to remove particulate matter. Contamination of urine with water or any form of detergent (e.g. from cleaning the floor) and faeces has to be avoided since this can render hormone levels immeasurable or can substantially alter hormone concentrations, respectively. Because urine samples are typically single voidings, urinary hormone measures have to be corrected by a measure of urine concentration which can differ substantially between samples due to differences in water intake and urine volume production. Indexing urinary hormone levels can either be achieved by urinary creatinine (a protein breakdown marker) or specific gravity (see Anestis et al., 2009 for comparison of both methods).

\subsubsection{Storage of urine samples}

Urinary steroids (and creatinine) are stable for at least $24 \mathrm{~h}$ at room temperature and for a few days at $4{ }^{\circ} \mathrm{C}$ (Kesner et al., 1995). However, freezing as soon as possible once samples have been collected is recommended (particularly for measurement of peptide- and proteo-hormones which are more sensitive to degradation) and represents the most common and preferred method of long-term storage. For analysis of gonadotropins (LH, FSH), a preservative (glycerol) has to be added immediately to the urine to prevent dissociation of the molecules' subunits (Livesey et al., 1983). Although steroid hormones usually tolerate multiple thaws, in principle thawing and re-freezing of the urine should be generally avoided. Small amounts of urine $(0.2 \mathrm{ml})$ can also be absorbed on filter paper (Shideler et al., 1995 for macaques) and stored dry (using silica gel), a "field-friendly" method when freezing samples is not possible (Knott, 1997; Marshall and Hohmann, 2005). Although resulting hormone profiles generated from urine-soaked filter paper usually parallel those generated from frozen urine (macaques: Shideler et al., 1995), the procedure introduces more analytical steps and therefore needs to be carefully controlled.

\subsubsection{Type of urinary assays}

Hormones in urine are excreted predominantly in a conjugated (water-soluble) form, either as mono- or multiconjugated sulphates or glucuronides. These can be either measured directly in appropriately diluted urine using conjugate assays (e.g. Heistermann and Hodges, 1995; Shideler et al., 1994) or as the free form after cleavage of the conjugate using enzymatic hydrolysis or solvolysis followed by use of an assay designed to measure the unconjugated compound (Eastman et al., 1984; Ziegler et al., 1996). In case of enzymatic hydrolysis, application should be viewed with caution when using enzyme preparations from $\mathrm{He}$ lix pomatia since these contain enzymes other than glucuronidase/arylsuphatase which can result in hormone transformation (see Hauser et al., 2008).

\subsubsection{Examples of application}

In terms of application, available data show that reliable information on female reproductive function can be obtained by the direct measurement of oestrone conjugates (E1C) and pregnanediol-3-glucuronide (PdG), which represent abundant urinary metabolites of oestradiol and progesterone, respectively, in most primate species. Analysis of these two groups of reproductive hormones is so far the most widely and successfully used approach for monitoring changes in ovarian activity (incl. timing of ovulation) and pregnancy in a wide range of primates (see Table 1 in Hodges et al., 2010 for references), incl. laboratory primates, namely macaques (Shideler et al., 1990) and marmosets (Eastman et al., 1984; French et al., 1996). In rhesus monkeys (Macaca mulatta), the non-specific measurement of C19/C21-progesterone metabolites (e.g. androsterone, 20 $\alpha$ dihydroprogesterone) has also shown to be useful for monitoring female reproductive status (Shideler et al., 1993a). In a number of studies, urinary steroid measurements are supplemented by the measurement of gonadotropins (e.g. when information on follicular development, timing of the ovulatory LH peak and/or excretion of chorionic gonadotropin during early pregnancy is required (e.g. French et al., 1996; Ziegler et al., 1987, 1990).

Information on the measurement of androgens in primate urine is surprisingly limited. To date, most studies have measured immunoreactive testosterone as a marker of male androgen status (e.g. Maggioncalda et al., 1999; Robbins and Czekala, 1997; Ziegler et al., 2000), although native testosterone itself represents a relatively minor component in the urine of primates (Hagey and Czekala, 2003; Möhle et al., 2002). There is some evidence that measurement of urinary 5-reduced androstanes might better reflect testicular endocrine activity in primate males, although there can be considerable variation in urinary androgens even among closely related species (Hagey and Czekala, 2003; Möhle et al., 2002).

Since most types of stressors induce an increased release of stress hormones (in most mammals and all primates mainly cortisol) from the adrenal gland, glucocorticoid output is commonly used as an endocrine marker of stress. Concerning urinary measurements, quantification of urinary cortisol has been shown to provide a reliable method for monitoring stress hormone output in a variety of primate species 
(Crockett et al., 1993; Robbins and Czekala, 1997; Smith and French, 1997; Whitten et al., 1998b). Since native cortisol is, however, quantitatively of little importance, measurement of the more abundant $5 \beta$-reduced cortisol metabolites might at least in some species be more suitable (Bahr et al., 2000; Klinkova et al., 2008).

\subsection{Hormone analysis from faeces}

Although in most captive situations urine samples can be collected regularly, in certain situations (e.g. group-living animals) this may be difficult. In addition, some primate species excrete insignificant amounts of hormones in the urine, with primary hormonal excretion found in the faeces (Perez et al., 1988; Ziegler et al., 1989). In these cases, faecal hormone analysis represents a suitable alternative to urinary hormone measurements. However, in contrast to urine, the measurement of peptide-/proteo-hormones and catecholamines has, until now, not been possible from primate faeces because these hormones are presumably either not excreted into faeces or only as heavily degraded compounds which are not detectable by the assay techniques used.

\subsubsection{Faecal sample collection}

One important advantage of faecal analysis is the ease of sample collection which does (unlike urine collection) usually not require a separation of animals so that any disruption of the individual(s) and its (their) activity can be completely avoided. Faecal sample collection can be facilitated by feeding focal animals with coloured food items (using food dyes, Stavisky et al., 2001) or different sorts of seeds/grains (e.g. wheat, millet; Fuller et al., 2010) by which the faeces are marked and therefore can be easily assigned to the respective individual(s). A 1-3 g portion (thumb-nail size) of faeces is sufficient for analysis. Since steroids can be unevenly distributed in a faecal bolus, the complete sample should be homogenized (e.g. by gloved hand or using a spatula) prior to collection if only a portion of it will be collected. Any contamination of faeces with urine (and water) has to be avoided as this may alter hormone levels (Wasser et al., 1988).

\subsubsection{Diurnal variation and storage of faecal samples}

Since faeces owing to an extended intestinal passage time (see below) represents pooled endocrine activity over a longer period than urine, a diurnal pattern of hormones as often seen in urinary hormone excretion (see above) is less likely to be present in faeces. However, the potential for it to exist remains, particularly in small-bodied species in which faecal passage rate is high (e.g. callitrichids: Löttker et al., 2004; Sousa and Ziegler, 1998). Therefore, like urine, faecal samples should be collected at roughly the same time each day.
One concern with faecal hormone analysis is that since faeces contain a large amount of gastrointestinal bacteria, breakdown of hormones due to bacterial metabolism is very likely and can result in alterations of steroid concentrations in unpreserved samples. Since these processes can occur within a few hours (Wasser et al., 1988), the interval from sample collection to preservation has to be kept to a minimum. Preferably faecal samples should be kept cool upon collection (e.g. in an insulated box with cool packs) until freezing at $-20^{\circ} \mathrm{C}$, which is the most effective and recommended way of preserving faeces for prolonged periods of time.

\subsubsection{Faecal hormone measurement}

Unlike urinary analysis where direct (non-extraction) assays can often be used (see above), measurement of hormones from faeces always requires an extraction step prior to assay and is usually associated with increased labour and cost of processing samples. Various extraction methods have been described, the most common used involving extraction into watery solutions of ethanol or methanol (40-80\%) by simple shaking (e.g. Heistermann et al., 1995). Hormones can then be measured directly from the supernatant following centrifugation of the faecal suspension. Whilst urinary steroids are usually excreted in a conjugated form, unconjugated (free) metabolites generally predominate in faeces, although exceptions occur (e.g. callitrichids: Ziegler et al., 1996). Assays for the measurement of hormones in faeces are therefore usually designed to measure the unconjugated portion, although the use of conjugate assays (e.g. E1C, PdG, see above) can also be successful, particularly when the antibody involved shows a substantial cross-reactivity with the unconjugated steroid metabolites excreted (Daspre et al., 2009; Heistermann et al., 2001; Shideler et al., 1993a). In species where the excretion of conjugates predominates (see above), hydrolysis or solvolysis following faecal extraction can improve results (see Ziegler et al., 1996).

\subsubsection{Type of information generated from faeces}

As with urinary measurements, the amount of faecal hormones has to be adjusted to compensate for the total volume of faeces produced. This is generally accomplished by expressing hormone levels per unit mass (gram), using either the wet weight or dry weight of the faeces. Since faecal samples can vary considerably in consistency and natural water content, freeze-drying (and subsequent pulverising) samples prior to extraction is a useful procedure as it can adjust for these differences and, furthermore, allows non-faecal material (seeds, stones, undigested fibre) to be easily removed which both can improve results (Wasser et al., 1988; Wasser et al., 1993).

Generally, hormone data from faeces correspond well with those obtained from serum or urine and thus provide results of principally similar validity (e.g. Cavigelli, 1999; 
Heistermann et al., 1993; Shideler et al., 1993b; Wasser et al., 1988). However, the fact that steroid metabolites in faeces represent pooled endocrine activity over several hours or days (see below) leads to a dampening effect in hormone levels, making faecal hormone measurements less sensitive for detecting short-term endocrine responses to acute situations (e.g. stress of a single event).

\subsubsection{Examples of application}

In terms of application, oestrogen and progesterone metabolite measurements in faeces have been widely applied to monitor female reproductive function in a whole range of primate species. In this respect, the measurement of oestradiol or oestrone (or a collective measurement of both) which is often used in combination with the determination of progesterone metabolites (pregnanediones and/or hydroxylated pregnanes) has generally proven informative for assessing ovarian activity and monitoring pregnancy in a wide range of primates of all major taxa (see Table 2 in Hodges et al., 2010 for references).

Compared with the situation in females, monitoring male gonadal endocrine activity through measurement of faecal androgens is still limited, although its application has increased substantially over the last few years. In most cases, testosterone assays have been successfully applied (e.g. Beehner et al., 2006; Brockman et al., 2001; Setchell et al., 2008), although native testosterone is barely present in faeces (Möhle et al., 2002). The measurement of 5-reduced androstanes has also been successfully used to monitor androgen status in male primates (Girard-Buttoz et al., 2009). However, since Old World monkeys and Great Apes secrete large amounts of androgens of non-testicular (e.g. adrenal) origin, such as DHEA, any faecal androgen measure in species of these taxa should be viewed with caution given that co-measurement of metabolites from DHEA my potentially confound assessment of testicular androgens due to potentially similar metabolic pathways of the two hormones (Möhle et al., 2002). Therefore, a specific assessment of testicular endocrine activity (rather than a measurement of overall androgen status) from faecal measurements may remain difficult in these taxa.

Measurement of cortisol metabolites in primate faeces has recently found widespread application for investigating the stress axis. In the majority of studies, a cortisol assay has been applied, although native cortisol is barely detectable in the faeces of the majority of primate species (Bahr et al., 2000, but see Heistermann et al., 2006). Despite the fact that a cortisol measurement can yield useful information on adrenal function (e.g. Bergman et al., 2005; Cavigelli, 1999; Heistermann et al., 2006), a group-specific measurement of more abundant metabolites of cortisol present in primate faeces is likely to provide results of higher validity in most species and will also have a greater potential for cross-species application (Fichtel et al., 2007; Heister- mann et al., 2006; Ostner et al., 2008). Since such groupspecific assays may, however, cross-react with structurally related testosterone metabolites (Heistermann et al., 2006), a potential co-measurement of metabolites that do not originate from cortisol should be taken into account when a faecal glucocorticoid assay is selected for use in a given species.

\subsection{Hormone analysis from saliva}

In contrast to urinary and faecal hormone concentrations which provide a cumulative measure of circulating hormone levels over a certain time period, saliva provides a sensitive reflection of acute changes in blood hormone concentrations and thus allows a real-time assessment of endocrine status. Since this measurement, however, provides point-in-time information comparable to that generated from blood, salivary hormone levels are strongly affected by episodic and diurnal fluctuations in hormone secretion (e.g. Kutsukake et al., 2009) and any hormone change that may have occurred as a result of environmental disturbance shortly before sampling. Hormone levels in saliva can therefore be highly variable within short time periods, even within the same individual, making interpretation of hormonal data from saliva potentially more difficult.

\subsubsection{Saliva collection and examples of application}

Collection of saliva is typically accomplished by training or enticing animals to chew for a couple of minutes on a dental rope or cotton pad (e.g. Ange-van Heugten et al., 2009; Hohmann et al., 2009; Pearson et al., 2008; von Engelhardt et al., 2000). This procedure allows samples to be collected voluntarily from animals on a regular basis and under various housing conditions, including group-living. Samples should be frozen after collection and usually analysis requires an extraction step with an organic solvent prior to assay. Because salivary hormones are structurally identical with the native compounds in circulation, problems associated with hormone metabolism and species specificity in steroid metabolite excretion (as potentially encountered with urine/faecal analysis, see below) do not occur with saliva. Thus, salivary hormones can be measured easily using assays (or commercially available assay kits) designed to measure the native hormone.

Despite the potential utility of assessing endocrine status via saliva, until to date the procedure has been applied to only a few primate species. Most of the studies have involved analysis of salivary cortisol to assess adrenal activity in relation to behaviour and acute stress (e.g. Ange-van Heugten et al., 2009; Cross et al., 2004; Hohmann et al., 2009; Kuhar et al., 2005), although the measurement of reproductive hormones has also been reported (DiGiano et al., 1992; von Engelhardt et al., 2000). 


\subsection{Hormone analysis from hair}

Steroid hormones from blood are able to diffuse into the cells of the hair follicle and subsequently become deposited in the hair shaft from which they can be measured (Koren et al., 2002). Hair sampling is usually accomplished by shaving hair from certain parts of the body (e.g. Davenport et al., 2006); however, since animals have at least to be restrained for this procedure, the method is not completely non-invasive. For hormone measurement, the hair is either cut into small pieces or ground to a fine powder (e.g. using a ball mill) from which hormones are extracted with an organic solvent (see Davenport et al., 2006). While the endocrine measure from hair is unaffected by acute stress (including that caused by handling during hair collection), external contamination of the hair surface with hormones from sweat, saliva (e.g. as a result of self-grooming or being groomed) or blood is a potential source of error. The effect of any contamination can, however, be minimised or completely compensated for by washing the hair prior to hormone determination (Davenport et al., 2006).

\subsubsection{Type of information generated and examples of application}

Since hormones in hair do not reflect daily or hourly fluctuations in circulating hormones, hair does not allow fine monitoring of endocrine changes over short periods of time, but rather represents a method for determining long-term (i.e. weeks or months) activity of the endocrine system(s). For this reason, the type of information generated from hair is generally limited and its application thus restricted compared to options that endocrine analysis from saliva, urine and faeces offers (see above). So far, hormone analysis from hair in animal species has almost exclusively been used for assessing cortisol levels as a measure of (chronic) stress (e.g. Accorsi et al., 2008; Koren et al., 2002). To date, published reports on its use in primates are limited to the rhesus monkey (Davenport et al., 2006) and common marmoset (Clara et al., 2008) where it has also been used as an index of adrenal activity.

\section{General considerations}

\subsection{Species variation in hormone metabolism and excretion}

While hormones in saliva and hair are structurally the same compounds as those circulating in blood, hormones in urine and faeces represent metabolic products of the native hormone(s) as a result of a series of chemical changes before their elimination from the body. The nature and extent of these metabolic processes can differ substantially between species, resulting in the presence of a vast number of different metabolites of the same parent hormone, even within closely related species (e.g. Bahr et al., 2000; Möhle et al.,
2002). Moreover, the route of excretion (whether a species excretes hormones preferentially into the urine or faeces) can also vary considerably among species, and between steroids within the same species (e.g. Ziegler et al., 1989). Given this extent of species variation, great care must be taken when applying urinary, but in particular faecal, endocrine measurements to a new species since extrapolation of findings from one species to another can be misleading (e.g. Heistermann et al., 2006; Schwarzenberger, 2007). A careful validation of hormone measurements for each species is therefore essential if the results are to be accurate and reliable with respect to the endocrine information in question (see Buchanan and Goldsmith, 2004; Heistermann et al., 2006; Touma and Palme, 2005).

Since measurement of hormones are usually carried out by immunological procedures (so-called immunoassays) utilising hormone- or hormone-group specific antibodies, selection of appropriate assay systems based on physiological and/or biological validation tests which prove that the measurement is biologically meaningful is of key importance (Heistermann et al., 2006; Touma and Palme, 2005). In this respect, assay testing should be carried out separately for even closely related species (see Heistermann et al., 2006; Möhle et al., 2002). Especially researchers who are not familiar with these non-invasive endocrine techniques but want to use them as a tool in their field of research need to be aware of this caveat.

Highly specific assays, i.e. those commercially available and designed to measure hormones in blood, can be successfully applied to measure hormones in saliva and hair, but are generally of limited value for the measurement of excreted hormone metabolites in urine and, in particular, faeces (Bahr et al., 2000; Heistermann et al., 2006), although exceptions do occur. A generally more suitable approach is to apply socalled group-specific assays by which a range of structurally similar metabolites are measured, thus providing a measurement of "total immunoreactivity" of a group of metabolites irrespective of the relative abundance of the individual components. The major benefit of this approach is that groupspecific assays can be usually applied to a wider range of species, thus helping to overcome the problems of species specificity in hormone metabolism (Palme, 2005; Heistermann et al., 2006; Schwarzenberger, 2007). Care needs to be taken, however, in order to avoid problems arising from the co-measurement of structurally related metabolites originating from different parent hormones (e.g. measurement of androgen metabolites in glucocorticoid assays; Heistermann et al., 2006) or different endocrine sources (e.g. comeasurement of androgens of adrenal and testicular origin; Möhle et al., 2002).

\subsection{Time lag in hormone excretion}

Timing of the collection of samples with respect to physiological or behavioural events varies with the type of sample. 
Whereas hormones enter saliva within 20-30 min after their appearance in blood and therefore almost mirror endocrine responses and states at the moment of sampling, hormones in excreta show considerable delay times and reflect events a certain time ago. In urine, the time lag is usually about 2 $8 \mathrm{~h}$ and generally consistent across species (e.g. Bahr et al., 2000; Möhle et al., 2002; Wasser et al., 1994). Time lags associated with faecal measurements are longer and more variable both between and within species since they generally reflect gut passage time which is largely affected by diet. In most large bodied primate species for which data are available, hormones are excreted in faeces $24-48 \mathrm{~h}$ after appearance in circulation (Bahr et al., 2000; Heistermann et al., 1993; Shideler et al., 1993b; Wasser et al., 1994), whereas in primates of smaller size, passage time can be faster (e.g. 416 h; Bahr et al., 2000; Möhle et al., 2002; Moorman et al., 2002). Characterisation of time lags is fundamental for a correct interpretation of hormonal results, e.g. when attempting to determine the timing of physiological events (e.g. ovulation) or test the interrelationship between hormone levels and behavioural events and states. Knowledge of delay times is also important for determining sampling frequency depending on the events that should be monitored.

\section{Concluding remarks}

Over the last three decades, non-invasive methodologies for monitoring endocrine status in primates have seen an enormous development which resulted in an increasing application of the techniques in all types of primatological studies, be they carried out in captivity or in the wild. Almost all of these studies have shown that once established and validated, non-invasive endocrine analysis can be an effective tool for assisting the management and breeding of primates in captivity and for improving our understanding of the complex biology of primates. The non-invasive nature of the methods is especially important as it largely avoids interference with the social setting, behaviour and physiology itself, thus providing usually more accurate representations of endocrine processes compared to the traditional procedure of measuring hormones from invasively collected blood samples. However, analysing hormones from non-invasively collected samples such as urine and faeces is not as easy as most people think, particularly not when dealing with a new species. In this respect, the importance of carefully validating each technique for each new species cannot be overemphasized as failure to do so could introduce considerable error and seriously compromise the validity of the results obtained. If these factors are taken into account though, the non-invasive techniques described here provide animal managers and researchers with unique opportunities to gather physiological data from an assortment of species living in a variety of environments.
Edited and reviewed by: E. W. Heymann

\section{References}

Accorsi PA, Carloni E, Valsecchi P, Viggiani R, Gamberoni M, Tamanini C, Seren E (2008) Cortisol determination in hair and faeces from domestic cats and dogs. Gen Comp Endocrinol $155: 398-402$

Anestis SF, Breakey AA, Beuerlein MM, Bribiescas RG (2009) Specific gravity as an alternative to creatinine for estimating urine concentration in captive and wild chimpanzee (Pan troglodytes) samples. Am J Primatol 71:130-135

Ange-van Heugten KD, van Heugten E, Timmer S, Bosch G, Elias A, Whisnant S, Swarts HJ, Ferket P, Verstegen MW (2009) Fecal and salivary cortisol concentrations in woolly (Lagothrix ssp.) and spider monkeys (Ateles spp.). Int J Zool doi:10.1155/2009/127852

Anzenberger G, Gossweiler H (1993) How to obtain individual urine samples from undisturbed marmoset families. Am J Primatol 31:223-230

Bahr NI, Palme R, Möhle U, Hodges JK, Heistermann M (2000) Comparative aspects of the metabolism and excretion of cortisol in three individual nonhuman primates. Gen Comp Endocrinol $117: 427-438$

Beehner JC, Bergman TJ, Cheney DL, Seyfarth RM, Whitten PL (2006) Testosterone predicts future dominance rank and mating activity among male chacma baboons. Behav Ecol Sociobiol 59:469-479

Bergman TJ, Beehner JC, Cheney DL, Seyfarth RM, Whitten PL (2005) Correlates of stress in free-ranging male chacma baboons, Papio hamadryas ursinus. Anim Behav 70:703-713

Brockman DK, Whitten PL, Richard AF, Benander B (2001) Birth season testosterone levels in male Verreaux's sifaka, Propithecus verreauxi: insights into socio-demographic factors mediating seasonal testicular function. Behav Ecol Sociobiol 49:117-127

Buchanan KL, Goldsmith AR (2004) Noninvasive endocrine data for behavioural studies: the importance of validation. Anim Behav 67:183-185

Cavigelli SA (1999) Behavioural patterns associated with faecal cortisol levels in free-ranging female ring-tailed lemurs, Lemur catta. Anim Behav 57:935-944

Clara E, Tommasi L, Rogers LJ (2008) Social mobbing calls in common marmosets (Callithrix jacchus): effects of experience and associated cortisol levels. Anim Cogn 11:349-358

Crockett CM, Bowers CL, Sackett GP, Bowden DM (1993) Urinary cortisol responses of longtailed macaques to five cage sizes, tethering, sedation, and room change. Am J Primatol 30:55-74

Cross N, Pines MK, Rogers LJ (2004) Saliva sampling to assess cortisol levels in unrestrained common marmosets and the effect of behavioral stress. Am J Primatol 62:107-114

Daspre A, Heistermann M, Hodges JK, Lee PC, Rosetta L (2009) Signals of female reproductive quality and fertility in colonyliving baboons (Papio h. anubis) in relation to ensuring paternal investment. Am J Primatol 71:529-538

Davenport MD, Tiefenbacher S, Lutz CK, Novak MA, Meyer JS (2006) Analysis of endogenous cortisol concentrations in the hair of rhesus macaques. Gen Comp Endocrinol 147:255-261

Deschner T, Kratzsch J, Hohmann G (2008) Urinary C-peptide as a method for monitoring body mass changes in captive bonobos (Pan paniscus). Horm Behav 54:620-626 
DiGiano L, Nagle CA, Quiroga S, Paul N, Farinati Z, Torres M, Mendizabal AF (1992) Salivary progesterone for the assessment of the ovarian function in the capuchin monkey (Cebus apella). Int J Primatol 13:113-123

Eastman SAK, Makawiti DW, Collins WP, Hodges JK (1984) Pattern of excretion of urinary steroid metabolites during the ovarian cycle and pregnancy in the marmoset monkey. $\mathrm{J}$ Endocrinol 102:19-26

Fichtel C, Kraus C, Ganswindt A, Heistermann M (2007) Influence of reproductive season and rank on fecal glucocorticoid levels in free-ranging male Verreaux's sifakas (Propithecus verreauxi). Horm Behav 51:640-648

French JA, Brewer KJ, Schaffner CM, Schalley J, HightowerMerritt D, Smith TE, Bell SM (1996) Urinary steroid and gonadotropin excretion across the reproductive cycle in female Wied's black tufted-ear marmosets (Callithrix kuhli). Am J Primatol 40:231-245

Fuller G, Margulis SW, Santymire R (2010) The effectiveness of indigestible markers for identifying individual animal feces and their prevalence of use in North American zoos. doi:10.1002/zoo.20339

Girard-Buttoz C, Heistermann M, Krummel S, Engelhardt A (2009) Seasonal and social influences on fecal androgen and glucocorticoid excretion in wild male long-tailed macaques (Macaca fascicularis). Physiol Behav 98:168-175

Hagey LR, Czekala NM (2003) Comparative urinary androstanes in the great apes. Gen Comp Endocrinol 130:64-69

Hauser B, Schulz D, Boesch C, Deschner T (2008) Measuring urinary testosterone levels of the great apes - Problems with enzymatic hydrolysis using Helix pomatia juice. Gen Comp Endocrinol 158:77-86

Heistermann M, Hodges JK (1995) Endocrine monitoring of the ovarian cycle and pregnancy in the saddle-back tamarin (Saginus fuscicollis) by measurement of steroid conjugates in urine. Am J Primatol 35:117-127

Heistermann M, Finke M, Hodges JK (1995) Assessment of female reproductive status in captive-housed hanuman langurs (Presbytis entellus) by measurement of urinay and fecal steroid excretion patterns. Am J Primatol 37:275-284

Heistermann M, Palme R, Ganswindt A (2006) Comparison of different enzymeimmunoassays for assessment of adrenocortical activity in primates based on fecal analysis. Am J Primatol 68:257-273

Heistermann M, Tari S, Hodges JK (1993) Measurement of fecal steroids for monitoring ovarian function in New-World primates, Callitrichidae. J Reprod Fertil 99:243-251

Heistermann M, Uhrigshardt J, Husung A, Kaumanns W, Hodges JK (2001) Measurement of faecal steroid metabolites in the liontailed macaque (Macaca silenus): a non-invasive tool for assessing female ovarian function. Primate Report 59:27-42

Hodges JK, Heistermann M (2011) Field endocrinology: monitoring hormonal changes in free-ranging primates. In: Setchell JM, Curtis DJ (eds) Field and Laboratory Methods in Primatology: A Practical Guide. Cambridge: Cambridge University Press 353370

Hodges JK, Brown JL, Heistermann M (2010) Endocrine monitoring of reproduction and stress. In: Kleiman DG, Thompson KV, Kirk Baer C (eds) Wild Mammals in Captivity: Principles and Techniques for Zoo Management. Chicago: The University of
Chicago Press 447-468

Hohmann G, Mundry R, Deschner T (2009) The relationship between socio-sexual behavior and salivary cortisol in bonobos: tests of the tension regulation hypothesis. Am J Primatol 71:223232

Kesner JS, Knecht EA, Krieg jr. EF (1995) Stability of urinary female reproductive hormones stored under various conditions. Reprod Toxicol 9:239-244

Klinkova E, Hodges JK, Heistermann M (2008) Urinary glucocorticoid levels in relation to socio-behavioral and reproductive parameters in captive-housed male chimpanzees. Primate Report 75:19-32

Knott CD (1997) Field collection and preservation of urine in orangutans and chimpanzees. Trop Biodiv 4:95-102

Koren L, Mokady O, Karaskov T, Klein J, Koren G, Geffen E (2002) A novel method using hair for determining hormonal levels in wildlife. Anim Behav 63:403-406

Kuhar CW, Bettinger TL, Laudenslager ML (2005) Salivary cortisol and behaviour in an all-male group of western lowland gorillas (Gorilla g. gorilla). Anim Welfare 14:187-193

Kutsukake N, Ikeda K, Honma S, Teramoto M, Mori Y, Hayasaka I, Yamamoto R, Ishida T, Yoshikawa Y, Hasegawa T (2009) Validation of salivary cortisol and testosterone assays in chimpanzees by liquid chromatography-tandem mass spectrometry. Am J Primatol 71:696-706

Lasley BL, Savage A (2007) Advances in the understanding of primate reproductive endocrinology. In: Campbell C, Fuentes A, KC M, Panger M, Bearder S (eds) Primates in perspective. New York: Oxford Univ Press. 356-369

Lerchl A, Kuderling I, Epple G (1991) Diurnal variations of urinary testosterone excretion in the male saddle-back tamarin (Saguinus fuscicollis). Primate Report 30:17-23

Livesey JH, Roud HK, Metcalf MG, Donald RA (1983) Glycerol prevents loss of immunoreactive follicle-stimulating hormon and luteinizing hormone from frozen urine. J Endocrinol 98:381-384

Löttker P, Huck M, Heymann EW, Heistermann M (2004) Endocrine correlates of reproductive status in breeding and nonbreeding wild female moustached tamarins. Int J Primatol 25:919-937

Maggioncalda AN, Sapolsky RM, Czekala NM (1999) Reproductive hormone profiles in captive male orangutans: implications for understanding developmental arrest. Am J Phys Anthropol 109:19-32

Marshall AJ, Hohmann G (2005) Urinary testosterone levels of wild male bonobos (Pan paniscus) in the Lomako Forest, Democratic Republic of Congo. Am J Primatol 65:87-92

Matteri RL, Durning M, Dierschke DJ, Handrow RR (1990) Determination of bioactive FSH in Rhesus monkeys (Macaca mulatta). Am J Primatol 21:295-305

Matteri RL, Roser JF, Baldwin DM, Lipovetsky V, Papkoff H (1987) Characterization of a monoclonal antibody which detects luteinizing hormone from diverse mammalian species. Domest Anim Endocrinol 4:157-165

Möhle U, Heistermann M, Palme R, Hodges JK (2002) Characterization of urinary and fecal metabolites of testosterone and their measurement for assessing gonadal endocrine function in male nonhuman primates. Gen Comp Endocrinol 129:135-145

Moorman EA, Mendoza SP, Shideler SE, Lasley BL (2002) Excretion and measurement of estradiol and progesterone metabolites 
in the feces and urine of female squirrel monkeys (Saimiri sciureus). Am J Primatol 57:79-90

Muller MN, Lipson SF (2003) Diurnal patterns of urinary steroid excretion in wild chimpanzees. Am J Primatol 60:161-166

Ostner J, Kappeler PM, Heistermann M (2008) Androgen and glucocorticoid levels reflect seasonally occurring social challenges in male redfronted lemurs (Eulemur fulvus rufus). Behav Ecol Sociobiol 62:627-638

Palme R (2005) Measuring fecal steroids: guidelines for practical application. Ann NY Acad Sci 1046:75-80

Pearson BL, Judge PG, Reeder DM (2008) Effectiveness of saliva collection and enzyme-immunoassay for the quantification of cortisol in socially housed baboons. Am J Primatol 70:11451151

Perez L, Czekala NM, Weisenseel KA, Lasley BL (1988) Excretion of radiolabeled estradiol metabolites in the slow loris (Nycticebus coucang). Am J Primatol 16:321-330

Prescott MJ, Buchanan-Smith HM (2003) Training nonhuman primates using positive reinforcement techniques. J Appl Anim Welf Sci 6:157-161

Pryce CR, Schwarzenberger F, Döbeli M, Etter K (1995) Comparative study of oestrogen excretion in female New World monkeys: an overview of non-invasive ovarian monitoring and a new applicaton in evolutionary biology. Folia Primatol 64:107-123

Reeder DM, Kramer KM (2005) Stress in free-ranging mammals: Integrating physiology, ecology, and natural history. J Mammal 86:225-235

Robbins MM, Czekala NM (1997) A preliminary investigation of urinary testosterone and cortisol levels in wild male mountain gorillas. Am J Primatol 43:51-64

Schwarzenberger F (2007) The many uses of non-invasive faecal steroid monitoring in zoo and wildlife species. Int Zoo Ybk 41:52-74

Setchell JM, Smith T, Wickings EJ, Knapp LA (2008) Social correlates of testosterone and ornamentation in male mandrills. Horm Behav 54:365-372

Sherry DS, Ellison PT (2007) Potential applications of urinary Cpeptide of insulin for comparative energetics research. Am J Phys Anthropol 133:771-778

Shideler SE, Munro CJ, Taylor HW, Johl HK, Lasley BL (1995) Urine and fecal sample collection on filter paper for ovarian hormone evaluations. Am J Primatol 37:315

Shideler SE, Munro CJ, Tell L, Owitt G, Laughlin LS, Chatterton RT, Lasley BL (1990) The relationship of serum estradiol and progesterone concentrations to the enzyme immunoassay measurements of urinary estrone conjugates and immunoreactive pregnanediol-3-glucuronide in Macaca mulatta. Am J Primatol 22:113-122

Shideler SE, Ortuno AM, Mor n FM, Moorman EA, Lasley BL (1993a) Simple extraction and enzyme immunoassays for estrogen and progesterone metabolites in the feces of Macaca fascicularis during non-conceptive and conceptive ovarian cycles. Biol Reprod 48:1290-1298

Shideler SE, Savage A, Ortuno AM, Moorman EA, Lasley BL (1994) Monitoring female reproductive function by measurement of fecal estrogen and progesterone metabolites in the whitefaced saki (Pithecia pithecia). Am J Primatol 32:95-108

Shideler SE, Shackleton CHL, Moran FM, Stauffer P, Lohstroh PN, Lasley BL (1993b) Enzyme immunoassays for ovarian steroid metabolites in the urine of Macaca fascicularis. J Med Primatol 22:301-312

Smith TE, French JA (1997) Social and reproductive conditions modulate urinary cortisol excretion in black tufted-ear marmosets (Callithrix kuhli). Am J Primatol 42:253-267

Sousa MBC, Ziegler TE (1998) Diurnal variation on the excretion patterns of fecal steroids in common marmoset (Callithrix jacchus) females. Am J Primatol 46:105-117

Stavisky RC, Whitten PL, Hammett DH, Kaplan JR (2001) Lake pigments facilitate analysis of fecal cortisol and behavior in group-housed macaques. Am J Phys Anthropol 116:51-58

Touma C, Palme R (2005) Measuring fecal glucocorticoid metabolites in mammals and birds: the importance of validation. Ann NY Acad Sci 1046:54-74

von Engelhardt N, Kappeler PM, Heistermann M (2000) Androgen levels and female social dominance in Lemur catta. Proc R Soc Lond B 267:1533-1539

Wasser SK, Monfort SL, Southers J, Wildt DE (1994) Excretion rates and metabolites of oestradiol and progesterone in baboon (Papio cynocephalus cynocephalus) faeces. J Reprod Fertil 101:213-220

Wasser SK, Risler L, Steiner RA (1988) Excreted steroids in primate feces over the menstrual cycle and pregnancy. Biol Reprod 39:862-872

Wasser SK, Thomas R, Nair PP, Guirdy C, Southers J, Lucas J, Wildt DE, Monfort SL (1993) Effects of dietary fibre on faecal steroid measurements in baboons (Papio cynocephalus cynocephalus). J Reprod Fertil 97:569-574

Whitten PL, Brockman DK, Stavisky RC (1998a) Recent advances in noninvasive techniques to monitor hormone-behavior interactions. Yearb Phys Anthropol 41:1-23

Whitten PL, Stavisky R, Aureli F, Russell E (1998b) Response of fecal cortisol in stress in captive chimpanzees (Pan troglodytes). Am J Primatol 44:57-69

Ziegler TE, Bridson WE, Snowdon CT, Eman S (1987) Urinary gonadotropin and estrogen excretion during the postpartum estrus, conception, and pregnancy in the cotton-top tamarin (Saguinus oedipus oedipus). Am J Primatol 12:127-140

Ziegler TE, Carlson AA, Ginther AJ, Snowdon CT (2000) Gonadal source of testosterone metabolites in urine of male cottontop tamarin monkeys (Saguinus oedipus). Gen Comp Endocrinol 118:332-343

Ziegler TE, Matteri RL, Wegner FH (1993) Detection of urinary gonadotropins in callitrichid monkeys with a sensitive immunoassay based upon a unique monoclonal antibody. Am J Primatol 31:181-188

Ziegler TE, Scheffler G, Wittwer DJ, Schultz-Darken N, Snowdon CT, Abbott DH (1996) Metabolism of reproductive steroids during the ovarian cycle in two species of Callitrichids, Saguinus oedipus and Callithrix jacchus, and estimation of the ovulatory period from fecal steroids. Biol Reprod 54:91-99

Ziegler TE, Sholl SA, Scheffler G, Haggerty MA, Lasley BL (1989) Excretion of estrone, estradiol, and progesterone in the urine and feces of the female cotton-top tamarin (Saguinus oedipus oedipus). Am J Primatol 17:185-195

Ziegler TE, Snowdon CT, Warneke M, Bridson WE (1990) Urinary excretion of oestrone conjugates and gonadotrophins during pregnancy in the Goeldi's monkey (Callimico goeldii). J Reprod Fertil 89:163-168 